\title{
Our experience on oncoplastic breast surgery: Clinical report and mini review
}

\author{
Artan Bodeci ${ }^{1}$, Euglent Hoxha ${ }^{1}$, Agim Karaj ${ }^{1}$, Myzafer Kaci $^{2}$, Rudin Domi ${ }^{3}$ \\ ${ }^{1}$ Division of Oncology, Department of Surgery, University Hospital Center "Mother Teresa", Tirana, Albania \\ ${ }^{2}$ Division of General Surgery, Department of Surgery, University Hospital Center "Mother Teresa", Tirana, Albania \\ ${ }^{3}$ Division of Anesthesia and Intensive Care, Department of Surgery, University Hospital Center "Mother Teresa", Tirana, Albania
}

Email address:

artanbodeci@aol.com (A. Bodeci)

\section{To cite this article:}

Artan Bodeci, Euglent Hoxha, Agim Karaj, Myzafer Kaci, Rudin Domi. Our Experience on Oncoplastic Breast Surgery: Clinical Report and Mini Review. Clinical Medicine Research. Vol. 4, No. 1, 2015, pp. 17-20. doi: 10.11648/j.cmr.20150401.14

\begin{abstract}
Breast cancer presents a common form of cancer in women, associated with increased mortality, costs, and psychosocial problems. Breast conserving surgery became a serious alternative of radical mastectomy in early stages of breast cancer. This technique tends to have the same oncological results as radical mastectomy but with better cosmetic results. Several factors may have an impact of what surgical technique is preferred by the patients. Breast cancer staging, education level, rural or urban residence, and the relationship between the surgical team and the patient, are the most important factors that cam modify the surgical technique. Albanian population has some specific regarding residence, education level, and a great difident sense regarding physicians. Our trail through this retrospective descriptive study tends to present and explain the results in our population.
\end{abstract}

Keywords: Breast Cancer, Radical Mastectomy, Breast Conserving Surgery

\section{Introduction}

The breast cancer is becoming a modern epidemic, affecting 1 in 9 women (1), presenting the first ranking cancer in western populations. This is associated with increasing mortality rates and of course the costs of public health services Since 1990 the oncoplastic breast surgery (OBS) is gaining an important role in breast oncological surgery. OBS is initiated in 1930s but the last 20 years is established. Several authors had till 1930 reported their results. Keynes (2) had introduced his own techniques combined with radiotherapy, but the first results were in 1977 determined by Calle' study (3). These techniques are introduced and improved by several centers especially by Institute Curie (4). Using OBS, the surgeon can remove breast tumors but taking care of aesthetic appearance especially in ptosis or macromastia. OBS has several limits depending on aesthetic aspects, tumor size and location, and the breast size. The indications of radical mastectomy include widespread tumors, multifocal, and recurrent tumors. Several authors had demonstrated the psychological effects of these techniques $(5,6)$. We tend to demonstrate our experience of our institution on oncoplastic breast surgery.

\section{Our Study}

\subsection{Material and Methods}

This retrospective descriptive study is performed in the Oncologic Institute close University Hospital Center "Mother Teresa", Albania. There were enrolled 226 patients during the period 2009-2010. The indications of oncoplastic surgery in breast cancer were the treatment of breast cancer at early clinical-morphological stage and mastopathy. There were excluded the multiplex focalized and recurrent tumors. All the included patients underwent general anesthesia after the patients were diagnosed with breast tumors. The diagnosing protocol included mammography, axial computerized tomography, ultrasonography and preoperative cytology examination. The data were elaborated using student test, ANOVA, Kaplan Meier and log rank (Mantel-Cox), considering a significant $P$ value for $\mathrm{p} 0,05$.

\subsection{Results}

\subsubsection{Demographic Data}

There were involved 226 patients diagnosed with breast cancer, undergoing oncoplastic or mastectomy technique. The 
patients' age varied between 29-78 years old. The mean age was 48,49 years old with the confidence interval $95 \%$ [25.3-71.6]. Rural residence was faced in $37,6 \%$, whereas 62 , $4 \%$ were residents in urban zones. $36,7 \%$ of women included in the study had elementary education, $63,3 \%$ had mid school and universitary education. Table 1 summarizes the demographic features of the included patients.

Table 1. Demographic data of the patients involved in the study.

\begin{tabular}{lcc}
\hline Variables & $\mathbf{n}$ & $\%$ \\
\hline Residence & 85 & \\
Rural & 141 & 37.6 \\
Urban & & 62.4 \\
Education & 83 & \\
Elementary & 98 & 36.7 \\
Mid school & 45 & 43.4 \\
University & & 19.9 \\
\hline
\end{tabular}

\subsubsection{Surgical Techniques}

Oncoplastic surgery technique was performed in $71,2 \%$ of the patients, who had been diagnosed with early cancer's stage. During this period we performed $100(62,1 \%)$ breast plastic surgery using lateral mammaplasty technique and 61 (37, $9 \%)$ using Benelli' technique (periaerolar mammaplasty). No anesthetic and surgical complications were recorded. Table 2 demonstrates the surgical techniques.

Table 2. The performed surgical techniques.

\begin{tabular}{lll}
\hline Surgical techniques & $\mathbf{n}$ & $\mathbf{\%}$ \\
\hline Oncoplastic & 161 & 71.2 \\
Mastectomy & 65 & 28.8 \\
Total & 226 & 100 \\
\hline
\end{tabular}

\subsubsection{Local Recurrences}

Table 3. Recurrences and complications.

\begin{tabular}{lll}
\hline Variables & $\mathbf{n}$ & $\mathbf{\%}$ \\
\hline Tumor's recurrences & 7 & 3.1 \\
Short term complications & 3 & 1.3 \\
Long term complications & 0 & 0 \\
Recurrences appearing time & & \\
During the first postoperative year & 1 & 0.5 \\
During the third postoperative year & 3 & 1.3 \\
During the fourth postoperative year & 3 & 1.3 \\
\hline
\end{tabular}

\subsubsection{Comparing Analysis}

Table 4 summarizes the comparing analysis between oncoplastic and mastectomy surgical techniques. Using student test and ANOVA, we found that oncoplastic techniques were preferred especially in younger women, whereas older patients had preferred mastectomy. The mean age in oncoplastic group was 46, 36 and in mastectomy group was 53, 57 years old. This represented a significative " $p$ " value $(d=7.395 \% \mathrm{CI}] 4.1-10.6$ [ $\mathrm{p}<0.05)$. Higher the education, most preferred seems to be the oncoplastic technique demonstrated with significant "p" value $(p<0.05)$.

Table 4. Comparison of oncoplastic and mastectomy surgical techniques.

\begin{tabular}{llclll}
\hline Techniques & \multicolumn{3}{l}{ Oncoplastic } & \multicolumn{4}{l}{ Mastectomy } \\
\hline Variables & $\mathrm{n}$ & $\%$ & $\mathrm{n}$ & $\%$ & $\begin{array}{l}\mathrm{p} \text { in ANOVA } \\
<0.001\end{array}$ \\
Residence & & & & & \\
Rural & 48 & 57 & 37 & 43 & \\
Urban & 113 & 80 & 28 & 20 & \\
Total & 161 & 71 & 65 & 29 & \\
Education & & & & & $<0.001$ \\
Elementary & 39 & 47 & 44 & 53 & \\
Mid school & 82 & 83 & 16 & 17 & \\
University & 40 & 89 & 5 & 11 & \\
Total & 161 & 71 & 65 & 29 & \\
\hline
\end{tabular}

There are no significant statistical differences between groups regarding the surgical techniques and tumor recurrences. Using Kaplan-Meier and log rank statistical techniques, we found no significant statistical differences between groups (survival technique of log rank (Mantel-Cox) $=2.9$ with $\mathrm{p}>0.05$ ).

Table 5. Statistical comparison of recurrences and complications between both groups.

\begin{tabular}{|c|c|c|c|c|c|}
\hline & Oncoplastic & & Mastectomy & & $p$ in ANOVA \\
\hline Variable & $\mathrm{n}$ & $\%$ & $\mathrm{n}$ & $\%$ & \\
\hline Recurrences & 3 & 42.0 & 4 & 58 & $>0.05$ \\
\hline Short term complications & 1 & $33,3 \%$ & 2 & $67,7 \%$ & \\
\hline Recidives' appearing time & & & & & $>0.05$ \\
\hline 1-st postoperative year & 0 & & 1 & 100 & \\
\hline 3-rd postoperative year & 1 & 33 & 2 & 67 & \\
\hline
\end{tabular}

\section{Discussion}

Breast cancer presents the commonest form of cancer among women in developed countries and significantly increasing in many developing countries. Breast cancer presents is a leading cause of cancer death among women worldwide (7). Being more frequent in high-income countries, it is recently reported that about $50 \%$ of breast cancer cases and $58 \%$ of breast cancer deaths can occur in developing nations (7). In the United States the five-year survival rate among women with newly diagnosed breast cancer is 
approximately evaluated up to $89 \%$, whereas in low-income countries are estimated to be below $40 \%(8,9)$.

Several authors reported the same long term surviving rates comparing the breast-conserving surgery (oncoplastic) with surviving rates of women who undergo radical mastectomy. Breast-conserving surgery is therefore gold standard for women with relatively small breast cancers or early diagnosed stages (10). Veronesi et al compared breast-conserving surgery with modified radical mastectomy, founding fewer differences in the rate of local recurrences between the two groups than the difference with the Halsted procedure. They reported that women who were 45 years of age or younger at the time of surgery presented increased rate of recurrence of tumors in the same breast in the group that received breast-conserving therapy (10). The Veronesi' study confirmed that oncoplastic is associated with a high quality of life, increased awareness and participation in early-detection programs on the part of women. Several earlier studies confirmed the Veronesi' study results $(11,12)$. Another interesting study conducted by Fisher et al, compared lumpectomy with or without irradiation with radical mastectomy. He found that lumpectomy associated with irradiation is as effective as mastectomy, but guarantying better cosmetic results (13). They showed that if specimen's margin were tumor free, than the survival rate did not statistically differentiate between lumpectomy and radical mastectomy. In our serial, we confirmed the same findings as reported in literature regarding the advantages of breast conserving surgery in the early stages of breast cancer. We found no significant statistical differences between groups regarding the surgical techniques and tumor recurrences.

Another issue we must deal with was the relationship between age, education, and residence with the used surgical technique. Several authors had studied and published a lot of papers regarding that topic. Carey et al published a paper with interesting data. They found that older Africa American women with recurrences had decreased breast cancer specific survival comparing to caucasian-american counterparts. Epidemiological studies showed the highest prevalence of recurrences among African American women, especially younger premenopausal African Americans $(14,15)$. Of course this contributes in higher mortality rate, but also associated with other factors like socioeconomic, cultural and treatment difference as well (15). This racial disparity in survival, however, persists after adjustment for treatment distribution and access to health care (16).

Another study is focused on the relationship of breast cancer, ethnicity and age (17). Parise et al found Hispanics as the ethnic group with the highest percentage of women less than 41 years diagnosed with breast cancer. Rivero also studied the incidence of breast cancer in Hispanic women in Costa Rica (18). The higher proportion of triple negative tumors, advanced stage, and younger median age at diagnosis could lead to a worse cancer prognosis in that group (18). We recorded no relationship between ethnicity and breast cancer in our study because of homogeneity in our population.

Breast cancer is always associated with psychosocial issues.
Several authors had recently reported the psychosocial problems in women suffering from breast cancer. In one study conducted in Egypt, women diagnosed with cancer experienced unique stresses related to loss of fertility, changes in various social roles, body images, sexual concerns, and altered relationships $(19,20)$.

A study done by Taleghani et al showed that the majority of strategies used by Iranian women to cope with breast cancer were being positive on religious faith (21). Doumit et al stated in their study that Lebanese women regardless of their religious background, considered cancer to be something from God (22).

This study shows that urban Tanzanian women have incomplete knowledge of breast cancer risk factors, symptoms, and treatment. Beliefs in common myths and folklore relative to causes of breast cancer persist among the women surveyed (23). All these aspects are faced in our study, especially in rural zone. The women from rural residences had fear, no idea about the surgery, asking for the husband's permit or his opinion about the surgical technique. Women from urban zone were more focused on cosmetic issues and preferred breast cancer surgery vs. Mastectomy. The women from rural zones preferred radical mastectomy because of their mentality, lack of education, and reduced possibilities to follow up (financially, transport, or social problems). Finance is important in following up a patient suffering from breast cancer. This issue is reported by some studies.

Many advances in breast cancer control in high-income countries like the United States are attributed to attention to disease risk factors and symptoms, advances in early detection, and accessible and effective multimodality treatment (24), whereas low-income countries like Tanzania reported advanced-stage disease, resulting in limited therapeutic options and high mortality rates (25).

Albanian population has some unique features. In comparison with other developed western european countries, $46,3 \%$ of albanian population lives in rural areas whereas 53 , $7 \%$ lives in urban areas. These results are reported according the 2011 Census preelimnary results (26). In the past periods the albanian population lived in majority in rural areas, but after 1990 a huge demographic population movement fron rural to urban areas was verified. Nevertheless this movement was not associated with a significant impact in the psychosocial aspects. The psychosocial enviroment mostly remain the same. Albania is ranked in low-income countries, determining the presence of finance issues as well. The relationship between the physician and the patient remains fragile and a special one. The hallmarks of this relationship are fear from surgery, "shame" feeling to be visit by the doctor, mentality that surgery can further deteriorate the breast cancer, the patients relatives' opinion, lack finance resouces, reduced possibilities to be part of follow-up program etc. The surgeon must explain all the possible surgical techniques to the patient. After that a witten consensus must be obtained. The patient and her relatives must be ensured for all the surgical aspects, complications, follow-up programs, and adjuvat therapies regimen. The written informed consent is an important issue that the physician must deal with it. After the adequate 
explanations, it is patient's responsability to choose the kind of surgery. So this retrospective study helps the oncologic surgeon to better explain the advantages of breast conserving surgery, and finally taking the right decision regarding surgical technique.

\section{Conclusion}

We concluded that breast conserving surgery is as effective as radical mastectomy, ensuring better cosmetic benefits. Women from urban zones and with appropriate education's level mainly preferred breast conserving surgery.

\section{References}

[1] Anon. Breast cancer: incidence rises while deaths continue to fall, http://www.statistics.gov.uk [accessed January 2009].

[2] Keynes G. The place of radium in the treatment of cancer of the breast. Ann Surg 1937; 106:619e30.

[3] Calle R, Pilleron JP, Schlienger, et al. Conservative management of operable breast cancer. Cancer 1978; 42:2045e53.

[4] Berry MG, Fitoussi AD, Curnier A, Couturaud B, Salmon RJ. Oncoplastic breast surgery: A review and systematic approach. Journal of Plastic, Reconstructive \& Aesthetic Surgery (2010) $63,1233 \mathrm{e} 1243$.

[5] Al-Ghazal SK, Fallowfield L, Blamey RW. Comparison of psychological aspects and patient satisfaction following breast conserving surgery, simple mastectomy and breast reconstruction. Eur J Cancer 2000; 36:1938e43.

[6] Rowland JH, Desmond KA, Meyerowitz, et al. Role of breast reconstructive surgery in physical and emotional outcomes among breast cancer survivors. J Natl Cancer Inst 2000; 92:1422e9.

[7] Ferlay J, Shin HR, Bray F, Forman D, Mathers C, Parkin DM. Estimates of worldwide burden of cancer in 2008: GLOBOCAN 2008. Int J Cancer. 2010; 127(12):2893-917.

[8] National Cancer Institute. Surveillance Epidemiology and End Results. 2012. U.S. Department of health \& Human Services. Bethesda, MD, USA.

[9] Coleman MP, Quaresma M, Berrino F, et al. Cancer survival in five continents: a worldwide population-based study (CONCORD). Lancet Oncol. 2008; 9(8):730-56.

[10] Veronesi U, Cascinelli N, Mariani L, Greco M, Saccozzi R, et al. Twenty-year follow-up of a randomized study comparing breast-conserving surgery with radical mastectomy for early breast cancer. N Engl J Med 2002; 347:1227-32.

[11] Sarrazin D, Lê MG, Fontaine MF, Arriagada R. Conservative treatment versus mastectomy in $\mathrm{T} 1$ or small $\mathrm{T} 2$ breast cancer - a randomized trial. In: Harris JR, Hellman S, Silen W, eds. Conservative treatment of breast cancer: new surgical and radiotherapeutic techniques. Philadelphia: J.B. Lippincott, 1983:101-11.
[12] Fisher B, Bauer M, Margolese R, et al. Five-year results of a randomized clinical trial comparing total mastectomy and segmental mastectomy with or without radiation in the treatment of breast cancer. N Engl J Med 1985; 312:665-73.

[13] Fisher B, Anderson S, Bryant J, Margholese R, Duetch M, et al. Twenty-year follow-up of a randomized trial comparing total Mastectomy, lumpectomy, and lumpectomy plus irradiation for the treatment of invasive breast cancer. N Engl J Med 2002; $347: 1233-41$.

[14] Carey LA, et al. Race, breast cancer subtypes, and survival in the Carolina Breast Cancer Study. Jama. 2006;295(21):2492-502; Morris GJ, et al. Differences in breast carcinoma characteristics in newly diagnosed African-American and Caucasian patients: a single-institution compilation compared with the National Cancer Institute's Surveillance, Epidemiology, and End Results database. Cancer. 2007; 110(4):876-84.

[15] DeLancey JO, et al. Recent trends in Black-White disparities in cancer mortality. Cancer Epidemiol Biomarkers Prev. 2008; 17(11):2908-12.

[16] Jatoi I, Becher H, Leake CR. Widening disparity in survival between white and African-American patients with breast carcinoma treated in the US Department of Defense Healthcare system. Cancer. 2003; 98(5):894-9.

[17] Parise CA, Bauer KR, Caggiano V. Variation in breast cancer subtypes with age and race/ethnicity. Crit Rev Oncol Hematol. 2010; 76:44-52.

[18] Rivero S, Brenes C. Breast Cancer Characteristics and Survival in a Hispanic Population of Costa Rica. Breast Cancer: Basic and Clinical Research 2014: 8:103-108 doi:10.4137/BCBCR.S15854.

[19] Kiecolt-Glaser JK, McGuire L, Robles TF, Glaser R. Emotions, morbidity, and mortality: New perspectives from psychoneuroimmunology. Annu Rev Psychol. 2002; 53(1):83-107.

[20] Al-Moundhri M, Al-Bahrani B, Pervez I, et al. The outcome of treatment of breast cancer in a developing country Oman. Breast. 2004; 13:139-145.

[21] Taleghani F, Yekta ZP, Nasrabadi AN. Coping with breast cancer in newly diagnosed Iranian women. J Adv Nurs. 2006; $54: 265-272$.

[22] Doumit MA, Huijer HA, Kelley JH, El Saghir N, Nassar N. Coping with breast cancer: a phenomenological study. Cancer Nurs. 2010; 33:E33-E39.

[23] Morse et al. Breast Cancer Knowledge, Beliefs, and Screening Practices among Women Seeking Care at District Hospitals in Dar es Salaam, Tanzania. Breast Cancer: Basic and Clinical Research 2014:8 73-79 doi: 10.4137/BCBCR.S13745.

[24] Bray F, McCarron P, Parkin DM. The changing global patterns of female breast cancer incidence and mortality. Breast Cancer Res. 2004; 6(6):229-39.

[25] Burson AM, Soliman AS, Ngoma TA, et al. Clinical and epidemiologic profile of breast cancer in Tanzania. Breast Dis. 2010; 31(1):33-41.

[26] http://census.al/Resouces/Data/Census 2011/Instat_print\%20.pdf 